\title{
AUTOMATIZAÇÃO RESIDENCIAL E UTILIZAÇÃO DE FONTES DE ENERGIA LIMPA PARA DIMINUIÇÃO DO CONSUMO NAS REDES ELÉTRICAS.
}

\author{
Renata Cristina Oliveira Santos ${ }^{1}$ \\ Gabriel Lima Barbosa² \\ Ana Maria Castro Machado ${ }^{3}$ \\ Camila Pires Cremasco Gabriel $^{4}$
}

\begin{abstract}
RESUMO
Este trabalho abordará algumas das soluções que podem ser implantadas em residências para economia de energia a partir da revisão bibliográfica de artigos sobre o tema na intenção de demonstrar que é possível implantar casas automatizadas para que exista diminuição dos gastos com energia elétrica. Em meio ao sistema capitalista vigente na maioria dos países, vê-se o elevado consumo de produtos industrializados, tanto de bens duráveis quanto bem não duráveis, que associado ao maior poder de compra do consumidor fez com que houvesse um aumento considerável no consumo de energia elétrica nos últimos anos, o que justifica a investigação deste trabalho. Tendo em vista a grave crise hídrica na qual estamos passando, o desperdício, a falta de saneamento, e dos problemas de infraestrutura, entre outros fatores, pressionam a necessidade de buscar novas fontes de energia sendo a automação uma maneira de minimizar os gastos energéticos dentro de edifícios e residências e consequentemente a sobre carga na matriz energética brasileira.

PALAVRAS-CHAVE: Automação, economia, matriz energética.
\end{abstract}

\section{AUTOMATION RESIDENTIAL AND SOURCES OF ENERGY USE CLEAN FOR CONSUMPTION DECREASE IN ELECTRIC NETWORKS}

\author{
ABSTRACT \\ This paper will address some of the solutions that can be deployed in homes for energy savings from \\ the bibliographic review on the topic in an attempt to demonstrate that you can deploy automated \\ houses so that there is reduction in energy expenses. Amid the prevailing capitalist system in most \\ countries, one sees the high consumption of processed products both durable goods and nondurable \\ as that associated with increased consumer purchasing power caused there was a considerable \\ increase in energy consumption electrical in recent years, which justifies the investigation of this work. \\ In view of the severe water crisis in which we are passing, waste, lack of sanitation, and infrastructure

\footnotetext{
${ }^{1}$ Graduando de Engenharia de Biossistemas, Unesp- Câmpus de Tupã. renataoliveira1508@gmail.com.

${ }^{2}$ Graduando de Engenharia de Biossistemas, Unesp- Câmpus de Tupã.glbarbosa3105@gmail.com

${ }^{3}$ Graduando de Engenharia de Biossistemas, Unesp- Câmpus de Tupã

anamaria_castromachado@hotmail.com

${ }^{4}$ Professora Dra da Unesp- Câmpus de Tupã camila@tupa.unesp.br
} 


\title{
Periódica Eletrânica

problems, among other things, press the need to seek new sources of energy and automation a way to minimize energy expenditure within buildings and residences and therefore the load on the Brazilian energy matrix.

KEYWORDS: automation, economy, energy matrix.

\section{RESIDENCIAL Y FUENTES DE ENERGÍA LIMPIA PARA USO DISMINUCIÓN DEL CONSUMO EN REDES ELÉCTRICAS AUTOMATIZACIÓN}

\begin{abstract}
RESUMEN
En este trabajo se abordará algunas de las soluciones que se pueden implementar em los hogares para el ahorro de energía a partir de la revisión bibliográfica sobre el tema en un intento de demostrar que se puede implementar casas automatizadas para que haya reducción em los gastos de energía. Em médio del sistema capitalista que revalece em la mayoría de los países, se ve el alto consumo de produtos procesados tanto de bienes durables y no durables como la associada conun mayor poder adquisitivo de los consumidores causado huboun aumento considerable en el consumo de energía eléctrica en los últimos años, lo que justifica la investigación de este trabajo. En vista de la grave crisis del agua que estamos pasando, los residuos, la falta de saneamiento, y los problemas de infraestructura, entre otras cosas, pressione la necesidad de buscar nuevas fuentes de energía y automatización de una forma de minimizar el gasto de energia en edificios y residencias y, por tanto, la carga en la matriz energética brasileña.
\end{abstract}

PALABRAS CLAVE: automatización, la economía, la matriz energética.

\section{INTRODUÇÃO}

Segundo a ANEEL (2008), o consumo de energia em um país é um dos principais indicadores do desenvolvimento econômico e do nível de qualidade de qualquer sociedade. Ele reflete tanto o ritmo de atividade dos setores industrial, comercial e de serviços, quanto a capacidade da população para adquirir bens e serviços tecnologicamente mais avançados, como automóveis, eletrodomésticos e eletroeletrônicos.

Ainda segundo a ANEEL (2008), de maneira geral nota-se uma expansão no consumo de energia no país, e isto devido ao crescimento econômico e ao crescimento populacional. As energias renováveis se tornam cada vez mais atraentes como alternativa de micro geração distribuída uma vez que houve redução do preço de cédulas fotovoltaicas e aero geradores, já que atualmente aliado ao poder de compra do consumidor está o alto valor de conta de energia elétrica pago pelo brasileiro, considerada uma das contas mais elevadas no mundo. 


\section{Periódica Eletrônica

BARBOSA (2012), existem regras destinadas a reduzir barreiras para instalação de geração distribuída de pequeno porte, que incluem a micro geração, com até 100 kW de potência, e a mini geração, de 100 kW a 1 MW. Impostas pela (Resolução Normativa $n^{\circ} 482 / 2012$, de 17/04/2012), a norma cria o Sistema de Compensação de Energia, que permite ao consumidor instalar pequenos geradores em sua unidade consumidora e trocar energia com a distribuidora local. A regra é válida para geradores que utilizem fontes renováveis de energia (hídrica, solar, biomassa, eólica).

Dessa forma, a residência que utiliza este tipo de geração de energia além de reduzir, permite até zerar o valor da conta de luz. E também o consumo excedente será injetado no sistema da distribuidora, que utilizará o crédito para abater o consumo dos meses subsequentes. Os créditos poderão ser utilizados em um prazo de 36 meses e as informações estarão na fatura do consumidor, a fim de que ele saiba o saldo de energia e tenha o controle sobre a sua fatura.

Esta realidade se torna cada vez mais constante nos dias atuais, devido a popularidade dos temas sustentáveis que são consequência dos danos causados pelo crescimento exponencial e descontrolado da raça humana e que com - passar dos anos reflete a visível necessidade de mudar hábitos culturais predominantes em nossa sociedade na intenção de minimizar os prejuízos e não sobrecarregar o planeta.

O objetivo deste trabalho teve como finalidade ilustrar alguns benefícios da automatização e uso de energias limpas aliando deste modo, preservação ambiental, automatização e conforto residencial, mostrando alternativas para a economia do consumo de energia da rede elétrica em residências e edifícios.

\section{METODOLOGIA/ MÉTODOS DE ANÁLISE}

Trata-se de uma pesquisa bibliográfica, definida como integrativa. Para o levantamento bibliográfico, optou-se pela busca de artigos em periódicos nacionais e internacionais, abrange o período de 1998 a 2015 disponíveis nas bases de dados pertencentes à plataformas científicas CAPES, Parthenon e Scientific Electronic Library Online (SCIELO). A pesquisa foi limitada a artigos publicados em periódicos indexados latino-americanos. Foram utilizados os seguintes descritores: Energia 
solar, biocombustíveis, aquecedor solar, automação residencial, técnicas construtivas, consumo de energia, sustentabilidade.

\section{RESULTADO}

Este tópico foi baseado nos artigos sobre o assunto e nas discussões que envolvem geração de energia e automação em residências. Foram discutidas fontes de energia limpa que colaboram para a geração autônoma de energia elétrica suficientes para manter toda a rede doméstica estável e diversas atitudes que podem ser realizadas para diminuir ainda mais os gastos de energia tanto para consumidores de fontes de energia renovável quanto não renovável.

As questões envolvidas neste trabalho, são soluções para melhorar a relação entre o homem e o meio em que vive. E segundo SAUVÉ (2005) Os problemas relacionados ao meio ambiente, exige o desenvolvimento de habilidade de investigação crítica das realidades do meio em que vivemos e de diagnóstico de problemas que se apresentam. Trata-se inicialmente de tomar consciência de que os problemas ambientais estão essencialmente associados a questões socioambientais ligadas a jogos de interesse e de poder. Neste caso tratamos das polêmicas relacionadas a questões energéticas do país, procurando utilizar fontes de energia que não sejam de usinas térmicas ou hidrelétricas que tem grande participação em nossa matriz energética. $E$ buscando diminuir o consumo de energia da população que é apenas uma das vertentes que necessitam de energia, já que outras categorias como a indústria e a agricultura também necessitam.

\subsection{FONTES DE ENERGIA LIMPA PARA UMA RESIDÊNCIA}

Para concretizar a automatização residencial de maneira sustentável, fez-se um estudo das principais fontes de energia sustentáveis que podem ser implantadas em uma residência: 


\section{Periódica Eletrânica

\subsection{ENERGIA SOLAR}

Segundo MOTTA (2011), A energia solar, considerada a fonte primária de energia, é uma fonte renovável como forma de energia elétrica através de materiais termoelétricos e fotovoltaicos. Ela também proporciona um impacto ambiental mínimo, comparada com os demais métodos de geração energética. Outra vantagem é a fácil viabilidade e confiabilidade junto aos consumidores finais, já que elimina a necessidade de transporte por grandes distâncias, durando mais de 25 anos sem manutenção. Sua principal desvantagem é o seu custo inicial de instalação, além de um rendimento dependente das condições climáticas. Ou seja, pensando no mapa geográfico brasileiro, as condições onde ocorre maior incidência solar (Norte e Nordeste) possui melhor aproveitamento deste tipo de energia aplicada a geração fotovoltaica. De acordo com a RVq, (2015) O Brasil é um país privilegiado no contexto da energia fotovoltaica já que apresenta altos níveis de radiação solar e temos uma das maiores reservas de quartzo de qualidade e somos o quarto maior produtor de silício grau metalúrgico do mundo.

\subsubsection{FUNCIONAMENTO DE UMA CÉDULA FOTOVOLTAICA}

Ainda de acordo com MOTTA (2011), A conversão da radiação solar em energia elétrica é realizada através de células fotovoltaicas, construídas por materiais semicondutores, como o Silício. Quando a luz solar atinge a célula, uma quantidade da energia da luz é absorvida pelo semicondutor, liberando os elétrons com uma ligação mais frágil para fluir livremente. Esses elétrons fluem num sentido de acordo com o campo elétrico produzido pela célula fotovoltaica, e quando se cria um caminho para essa corrente elétrica, têm-se um painel solar.

A RVq, (2015) afirma que as células fotovoltaicas encontradas no mercado atualmente são, na grande maioria, células de silício, das quais existem três tipos. Podem ser de silício cristalino, que se subdividem em monocristalino e policristalino, ou podem ser de silício amorfo. Segundo dados de 2007 divulgados pelo CETEM,11 as células de silício monocristalino apresentam maior eficiência de conversão fotovoltaica, em torno de 1215\%, sendo que o valor máximo encontrado em laboratório foi de $25 \%$, e é possível encontrar células no mercado com eficiência de até $22,7 \%$. 
O sistema fotovoltaico é composto basicamente por um ou mais painéis fotovoltaicos, um controlador de carga e baterias. Dependendo da aplicação, também se faz necessário o uso de um inversor. Para uma residência tem-se a figura abaixo que mostra o funcionamento destas placas.

\section{Figura 1: composição do sistema fotovoltaico}

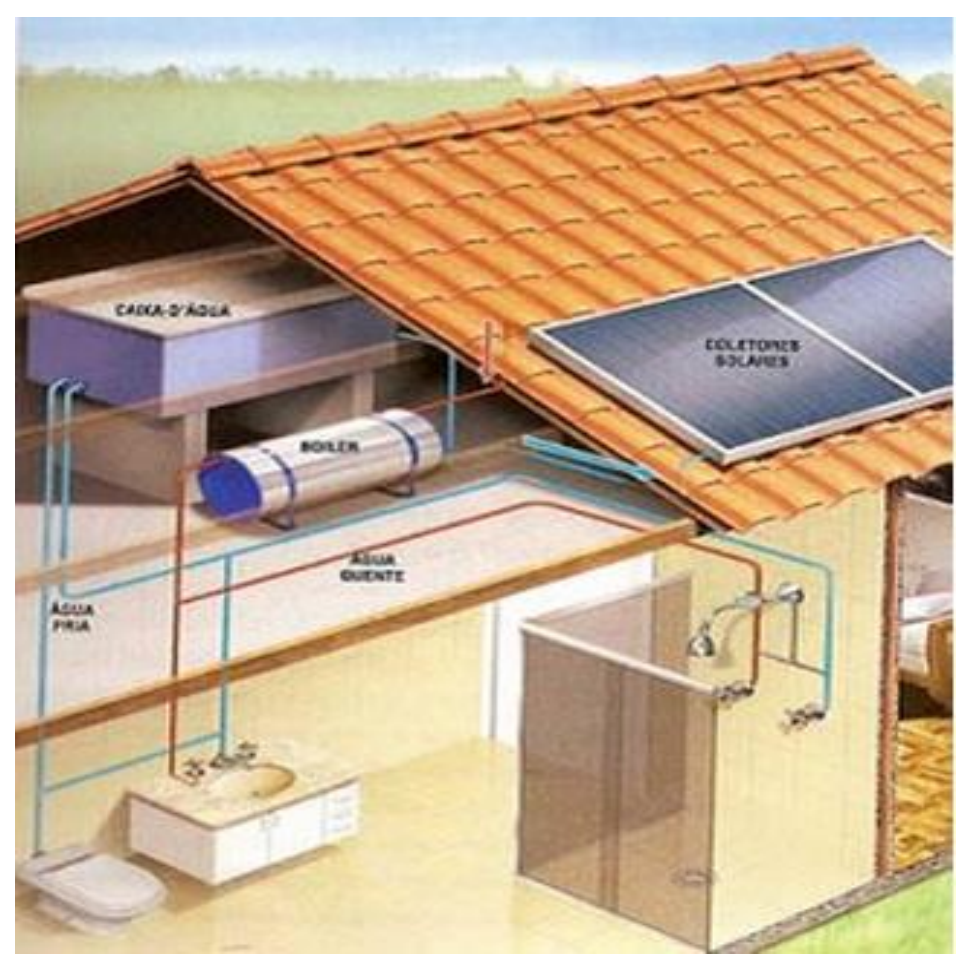

FONTE: BAIMA, (2004)

Segundo NEA (2006) Este processo é simples, sem emissão de gases poluentes ou ruídos e com necessidade mínima de manutenção. Os custos envolvendo todas estas etapas necessárias para a geração de energia devem ser computados no momento em que se compara a energia solar com as outras fontes. Devido à sua simplicidade, esta forma renovável de obter eletricidade possui diversas vantagens econômicas.

De acordo Motta, (2011) Afirma que os módulos fotovoltáicos são a unidade principal de um sistema fotovoltaico. Eles que realizam a conversão da luz solar em uma corrente elétrica contínua, chegando comercialmente a potências de 5 até 300 W. Lembrando que se faz necessário a presença de um controlador de carga e descarga de energia. 
Como afirma $R V q$, (2015) Apesar dessas características, no Brasil, a capacidade atual em geração de energia por sistemas fotovoltaicos é estimada em $20 \mathrm{MW}$, já que a instalação é muito cara e não há indústrias desse segmento no Brasil.

\subsection{AQUECIMENTO SOLAR DE GARRAFA PET}

Como afirma Pereira et al. (2006), Estudos realizados sobre a eficiência do coletor do projeto ASBC avaliam a eficiência térmica destes coletores solares utilizando materiais termoplásticos, usados na construção civil como forros modulares e tubos de PVC rígido.

De acordo com Mogawer; Souza (1998) A necessidade de implantação de aquecedores de baixo custo em residências populares é de grande importância para o desenvolvimento econômico e social, e seu dimensionamento é de grande importância para a instalação do sistema

Figura 2. Aquecedor solar construído com garrafas PET e caixas de leite Tetra

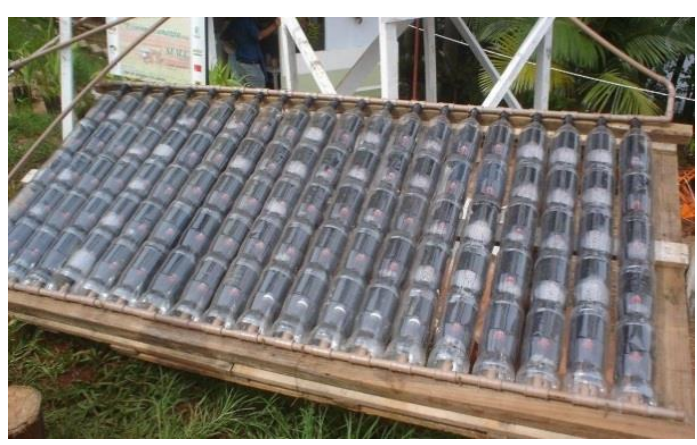

FONTE: (SEMA, 2008).

O princípio de funcionamento que melhor se adapta a sistemas simples, como ao aquecedor solar proposto é por termo sifão. Para isto é necessário que a instalação do coletor seja feita de forma que sua barra superior (2), associada à água quente, seja conectada na parte superior do reservatório (caixa d'água), enquanto a barra inferior (1), associada à água fria, seja conectada na parte inferior, conforme ilustra a Figura 3.

Esta diferença de altura garante a circulação da água no coletor devido à diferença de densidade entre água quente e a fria. À medida que a água esquenta 
nas colunas do coletor, ela sobe para a parte superior do reservatório pressionada pela água fria, que por ser mais pesada, flui para a parte inferior do coletor, empurrando a água quente para a parte de cima da caixa d'água.

Figura 3: Processo de termo-sifão de um sistema de aquecimento solar de água

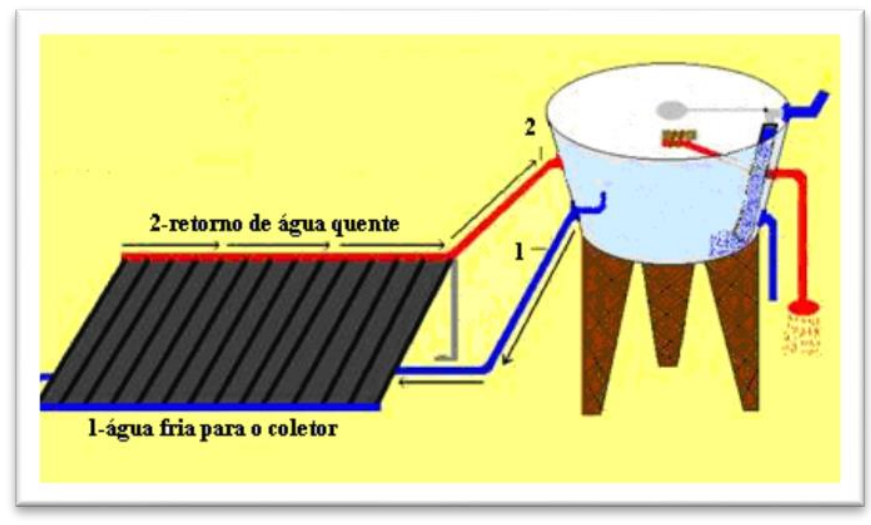

FONTE: adaptado de SEMA, (2008).

\subsection{BIOCOMBUSTÍVEIS}

RICA, (2012) O uso energético da biomassa apresenta diversos aspectos condicionantes. Em primeiro lugar, há que referir a questão da concorrência entre energia e alimentos. Esta poderá existir em países a dispor de reduzidas áreas agriculturáveis e de uma fronteira agrícola limitada, o que não impede o desenvolvimento da agro-energia desde que feito 0 adequado zoneamento/planejamento agrícola, no qual se contemple a delimitação das diferentes modalidades de cultura e utilização do solo (produção de alimentos, culturas de exportação, pecuária e agro-energia).No caso específico do Brasil, conforme atestam Costa e Hoeschl (2006), há a considerar o caso do biodiesel, combustível natural obtido a partir de fontes renováveis e destinado à utilização em motores ciclo-diesel. Na verdade, o biodiesel (enquanto biocombustível) apresenta um enorme potencial no que diz respeito ao alcance de objetivos sociais/ambientais, uma vez que pode vir a promover a fixação do homem ao campo (elemento promotor da formação de uma classe de pequenos/médios produtores agrícolas), estimular a criação de emprego, possibilitar a geração de renda e colaborar para a redução/minimização da emissão de gases que contribuem para as alterações climáticas globais. 


\section{Periódica Eletrânica

\section{ALTERNATIVAS DE DIMINUIÇÃO DO CONSUMO RESIDENCIAL}

Além da instalação de fontes de energia limpa para possibilitar a mínima dependência das redes elétricas, é ideal que seja explorado ao máximo os recursos básicos de automação para que tenha um maior controle no consumo por meio de sensores e de métodos eficientes de distribuição de energia no ambiente.

Sala (2006), cerca de $42 \%$ da energia elétrica produzida no Brasil é utilizada em edificações residenciais, comerciais e públicas. E o consumo de energia elétrica dentro de qualquer edificação cresce constantemente, pelo aumento dos números de eletroeletrônicos e do poder aquisitivo da população, sendo cada vez mais necessário a conscientização e o uso racional desse recurso.

Com base no gráfico abaixo, vê-se que os sistemas de iluminação e o chuveiro elétrico são os maiores consumidores de energia elétrica em uma residência

Figura 5. Estimativa de consumo por eletrodomésticos de acordo com uso hipotético de uma residência com consumo mensal médio de 220 kWh/mês. Dados ilustrat

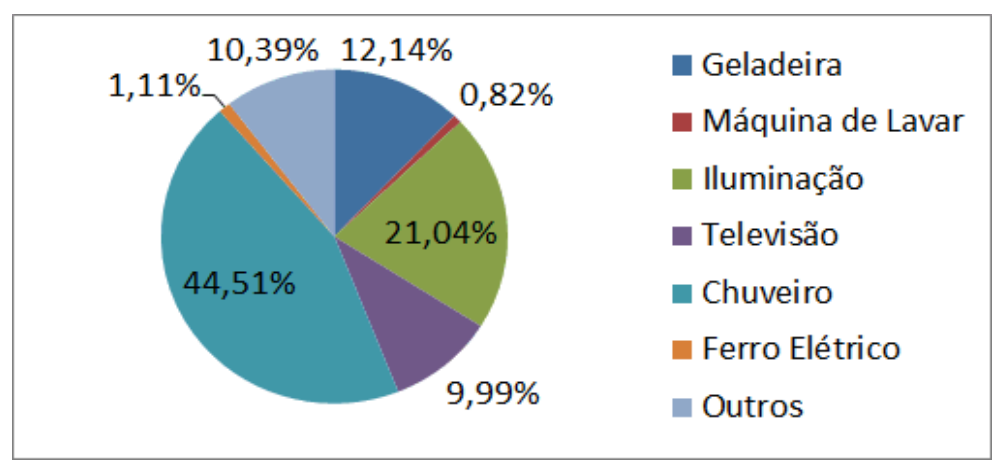

FONTE: 1) pesquisa de usos e posse de equipamentos - consumidor residencial urbano copel 2011.2) eletrobras - programa procel

É favorável na conta de luz do consumidor a utilização de aquecedores solares de garrafa pet para os chuveiros e torneiras elétricas, placas solares e também técnicas construtivas que minimizem os gastos energéticos residenciais, entre elas vale ressaltar as casas inovadoras e sustentáveis encontradas pelo mundo, um exemplo é a casa pet construída nas dependências da Fatec de Presidente Prudente, a casa conta com garrafas dispostas na horizontal e 
preenchidas com uma mistura de solo cimento, o que colaborou para o melhor conforto térmico do ambiente e consequentemente não necessita de ar condicionados para a região na qual se encontra.

Figura 6. Projeto Casa-Pet construída com garrafas pet e solo cimento

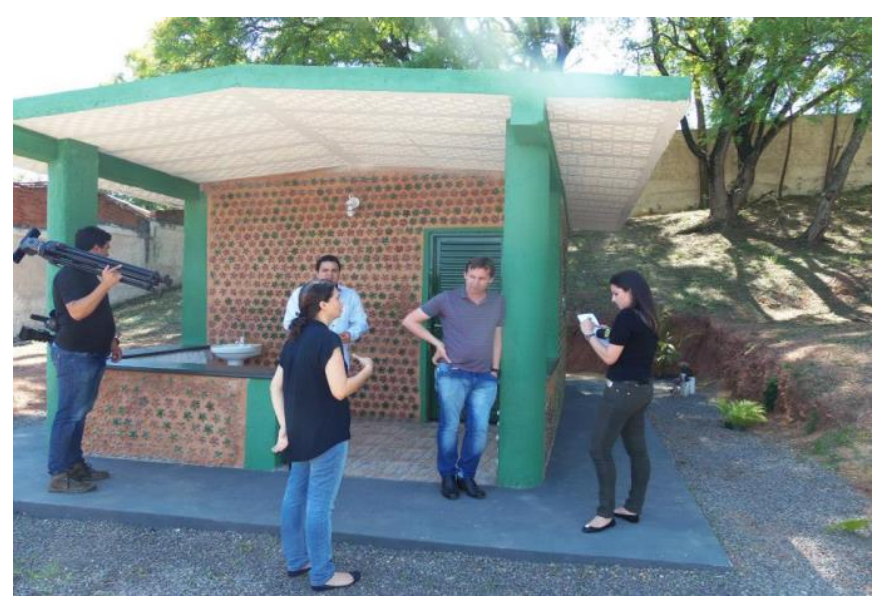

FONTE: CICLOVIVO

\subsection{MÉTODOS DE ILUMINAÇÃO PARA O APROVEITAMENTO DA LUZ SOLAR}

O ideal, seria aproveitar a luz do dia das mais diversas formas possíveis, já existem sistemas de persianas com sensores de movimento e componentes que aproveitam a luz do Sol de forma direta ou indireta. O fato é que quanto maior iluminação natural menor será o custo da conta de luz, porém como a iluminação natural depende de variáveis como tempo, época do ano, disponibilidade de luz solar etc, pode-se ter a necessidade de um complemento com luz artificial que também serve para o período noturno. Neste caso, dá-se prioridade as lâmpadas de LED que apesar de serem uma opção mais cara, apresentam vida útil longa e alta eficiência energética quando comparada as luzes fluorescentes ou incandescente, Motta, (2011) O uso de técnicas de iluminação natural permite até 50\% de economia de energia em iluminação. 
Figura 7. Comparação entre lâmpadas incandescentes, fluorescentes e LED

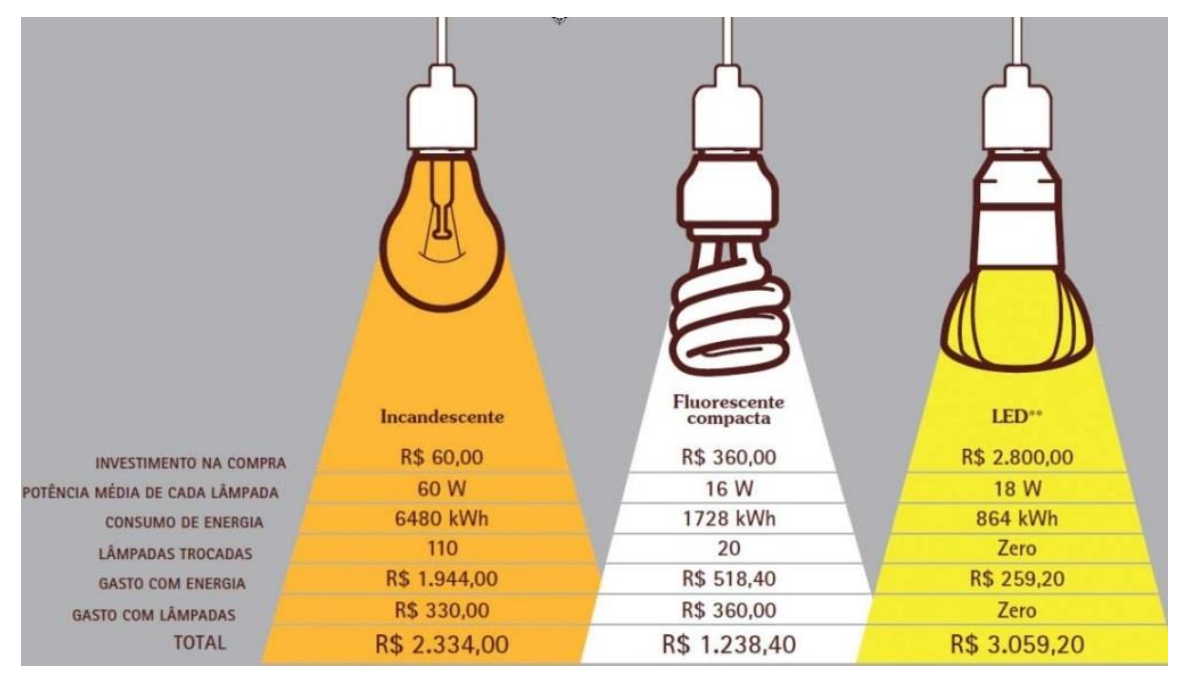

FONTE: Planeta(2011)

A iluminação lateral que nada mais é do que abertura de fendas verticais feitas nas paredes laterais garantindo assim maior luminosidade durante todo o período do dia. Algo semelhante leva o nome de laser cutpanel segundo MOTTA, (2012) feito com um painel de acrílico que é dividido em vários elementos retangulares através de cortes a laser, sua principal característica é a grande proporção de luz defletida em um ângulo maior de $120^{\circ}$, permitindo um maior alcance dentro da edificação. Os painéis podem ser de brise móvel, tendo ângulos diferenciados em cada estação do ano.

Outra técnica que é comercialmente vendida é o Solatube. Um sistema predominante em países desenvolvidos que é composto por uma cúpula formada de prismas refletores que recebem a iluminação solar e a reflete por dentro de um tubo espelhado, até chegar no interior do ambiente.

Segundo dados da empresa australiana conhecida por ser uma das pioneiras na fabricação desse sistema de iluminação (SOLATUBE), o preço deste produto é a partir de 399 dólares. Uma técnica bem mais em conta é a implantação de garrafas pet com um líquido de alta refração, que funciona como uma espécie de lente e ilumina a casa sem utilizar energia elétrica, apenas refletindo a luz do sol. 
Figura 8. Técnica de iluminação com base no sistema Solatube

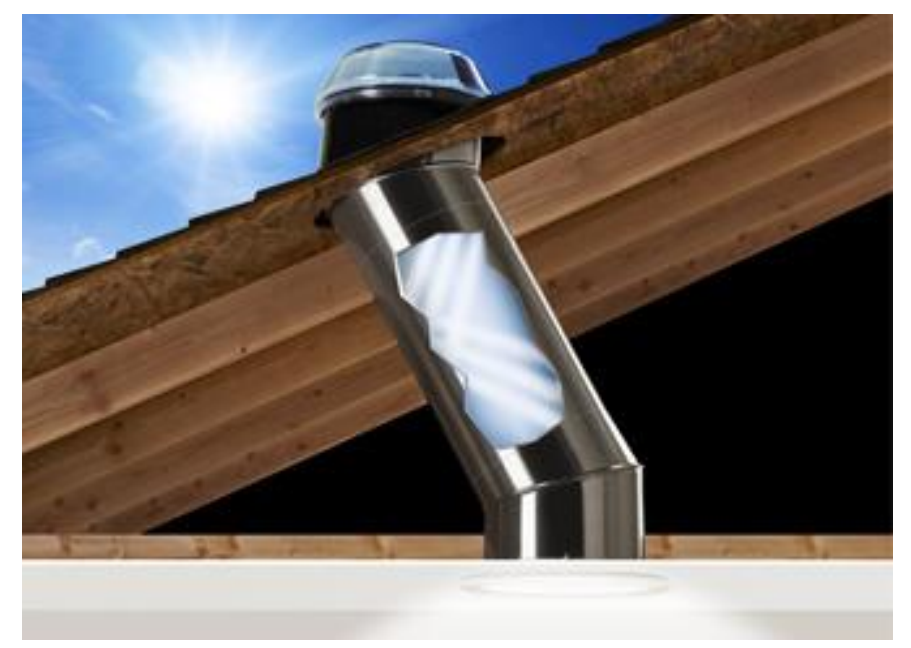

Fonte: SOLATUBE

\subsection{Sensores, inversores e controle de intensidade luminosa.}

A participação dos sensores de movimento quando colocados nos cômodos da casa colaboram para o controle de energia elétrica, ou seja, com isso deixa de existir a possibilidade de o consumidor esquecer um cômodo aceso. Um regulador automático de intensidade luminosa reduz os gastos de consumo e colabora a manutenção da luminosidade no ambiente, ou seja, o ajuste será feito de acordo com a necessidade de luz no cômodo, beneficiando o consumidor.

Os inversores permitem transformar uma corrente contínua proveniente de uma placa solar em corrente alternada para eletrodomésticos, diminuindo as chances de ter um curto circuito nos aparelhos da casa.

\section{RESULTADO}

Como afirma MOTTA, (2012) a eficiência energética pode ser aplicada na geração, distribuição, e também junto às instalações consumidoras. Através de melhorias nos sistemas de uso final de energia elétrica, pode-se reduzir o consumo sem interferir no desempenho. Essa redução favorece o setor elétrico, pois diminui futuros investimentos no parque de geração instalado para atender a demanda, e favorece também o usuário final, pois reduz os seus gastos com energia elétrica. De 


\section{Periódica Eletrânica

acordo com RICA, (2012) a questão ambiental não pode ser tratada separadamente da questão energética. Portanto, pode-se considerar que se vive hoje uma transição do Paradigma dos Combustíveis Fósseis (não renováveis) para o Paradigma das Energias Renováveis. A transição não é imediata e levará ainda algumas décadas. A PROCEL analisa por meio da Etiqueta Nacional de Conservação de Energia (ENCE) Geral que os aparelhos devem atingir índices mínimos de eficiência energética aliado aos possíveis métodos de economia de energia, fica evidente que a vantagem seria tanto para a sociedade quanto para o usuário e para o ambiente.

\section{CONCLUSÃO}

Atualmente existem diversas técnicas e métodos de redução e controle de energia, porém pouco exploradas devido a três fatores principais: custo inicial dos sistemas ainda são altos em comparação com o sistema de energia elétrica convencional, há pouca disseminação dessas técnicas no meio social, e também o fato do consumidor de modo geral, esperar um retorno financeiro imediato.

Tais fatos fazem com que a visão do brasileiro sobre temas como redução de energia elétrica e sustentabilidade sejam ligados somente às técnicas de aproveitamento de energia mais disseminadas na mídia, e que ainda são conhecidas por serem de alto custo, apesar de eficientes, como as placas solares. Entretanto, este trabalho mostra que existem sistemas com custo acessível e que mesmo que uma residência não conte com a participação de fontes de energia limpa, por meio da automação associada a técnicas construtivas de aproveitamento de luz, água, e melhoramento do conforto térmico, o consumo de energia elétrica fica reduzido. E se esta realidade tivesse maior alcance social e fosse implantada nas novas residências e condomínios a serem construídos, consequentemente diminuiria a sobrecarga na matriz energética do nosso país. Além disso é indispensável a conscientização dos brasileiros sobre a necessidade de se economizar energia elétrica 


\section{Periódica Eletrânica

\section{REFERÊNCIAS BIBLIOGRÁFICAS}

ANEEL. Agência Nacional de Energia Elétrica. Disponível em: <www.aneel.gov.br>. Acesso em: mai. 2015

BAIMA, M. C. Segredo da Casa Auto-Suficiente: Arquitetura e Construção. Brasília: Editora Abril, 2005.

Barbosa, Luís Fernando. M. Geração de energia renovável em residências: aplicação de tecnologias existentes. Guaratinguetá, 2012.

PET Casa: CICLOVIVO <www.ciclovivo.com.br> acesso em mai, 2015.

COSTA, F. C.; HOESCHL, H. C.. Gestão do conhecimento na cadeia produtiva de Biodiesel. In: CONGRESSO DA REDE BRASILEIRA DE TECNOLOGIA DE BIODIESEL, 1. Anais. Brasília: MCT/ABIPTI, 2006. p.30-34.

COSTA, F. J. P.. O papel da conservação nas políticas e programas direcionados ao setor energético. Dissertação (Mestrado em Planejamento Energético) - COPPE da Universidade Federal do Rio de Janeiro, Rio de Janeiro, 1990.

MOTTA, Rodolfo Rafael B. Técnicas de energia elétrica sustentável aplicadas em edificações. Guaratinguetá: UNESP. 2011.

PLANETA Sustentável: Lâmpadas Econômicas. Disponível em:

$<$ http://planetasustentavel.abril.com.br/noticia/energia/lampadas-economicas-gastoenergia-sua-contaluz-57380.shtml> Acesso em: 13/09/2011.

PROCEL. Avaliação do mercado de eficiência energética no Brasil. Rio de Janeiro: PROCEL, 2007

RENATO C. PEREIRA, Renato C. et. Al. Eficiência térmica de coletores solares de baixo custo CSBC, 2006. Disponível em: <http://www.metallum.com.br/17cbecimat/resumos/17Cbecimat-414005.pdf >. Acesso em: mai. 2015.

RODRIGUES, M.G; COSTA, F.J. P, Revista Ibero-Americana de Ciências Ambientais, Aquidabã, 2012, v.3, n.1, Universidade Federal do Rio de Janeiro, Brasil, Universidade de Santiago de Compostela, Espanha

Machado, C. T.; Miranda, F. S, Revista Virtual Química, Energia Solar Fotovoltaica: Uma Breve Revisão, Universidade Federal Fluminense, Rio de Janeiro, 2015.

SALA, L. G. Proposta de Habitação Sustentável para Estudantes Universitários. 87 f. Trabalho Conclusão de Curso (Graduação) - Universidade Regional do Noroeste do Estado do Rio Grande do Sul, ljuí, 2006. 
SAUVÉ Lucie, Educação Ambiental: possibilidades e limitações, educação e pesquisa, v.31, n. 2, p. 317-322, São Paulo, 2005

SEMA, Secretaria do Meio Ambiente e Recursos Hídricos do Estado do Paraná. Aquecedor Solar Construído com Materiais recicláveis. Disponível em:

<http://www.meioambiente.pr.gov.br/arquivos/File/meioambiente/solar.pdf>. Acesso em: mai. 2015.

SOLATUBE: Para sua Casa. Disponível em: <http://www.solatube.polirigido.com> Acesso em: mai, 2015.

TAMER MOGAWER, T.; SOUZA, T.M. de. Sistema solar de aquecimento de água para residências populares, [1998]. Disponível em:

<http://www.feagri.unicamp.br/energia/agre2004/Fscommand/PDF/Agrener/Trabalho\%2091.pdf >. Acesso em: mai. 2015. 